What is the office of the chain of ossicles? Why are there four bones joined together, instead of one only? Why not obliterate the fenestra rotunda or the fenestra ovalis, or even both of them, and by placing the vestibule in contact with the membrane of the tympanum. It is impossible, with our present knowledge of acoustics, to give satisfactory answers to these questions. The chain of bones, besides the power of altering the degrees of tension of the membranes to which its extremities are fixed, without doubt fills also the same office in the ear that the bridge does in stringed instruments, and the cavity in the drum. When one membrane of a drum is covered with sand, it is seen to vibrate and form itself into divisions when the other is struck, and this propagation varies according to the disposition of the cavity. The chain of ossicles is a kind of bridge suspended in the cavity of the tympanum, which not only propagates vibrations from one of its walls to the other, but also receives the shocks of air over the different parts of its surface. The membrane of the fenestra ovalis, which communicates with the restibule, where the nerve is found, certainly has its elasticity and tension better protected, by being placed in a cavity of air enclosed in the interior of the ear, than conld have been the case had it been directly in contact with the atmosphere. It is doubtless for the purpose of giving the ear a more varied and extended mode of action, that it has been provided with two openings furnished with membranes in the interior of the ear, and in proximity with the acoustic nerve; one of these being free, and the other in contact with the membrane of the tympantm, by the intervention of the chain, and hence susceptible of different degrees of tension. Hence is obtained a greater extent of function of the ear. These answers to the questions we asked ourselves, are certainly not the only ones which we may one day be able to give; but since the organ can exist, and perform its function without the chain of ossicles, and the membrane and cavity of the tympanum, we must admit, that they do not form an essential part of the ear, and that they only serve for its perfection and preservation.

I shall only say a few words upon the semicircular canals and the cochlea. It is generally supposed that the vibrations excited and transmitted by the solid walls in which the ear is implanted, are transinitted by these parts to the auditory nerve.

I shall rapidly pass over the physical characters of "sound," the comparison of different sounds with each other, and the limits at which sounds may be perceived. A shock, or an ex. citation of any kind, communicated to the anditory nerve, as we said at the beginning of this lecture, produces a sensation of sound. By the word "sound," we understand more precisely a sensation which continues uniform during a certain time, and is susceptible of being measured and compared. A "sound" differs, then, from a " noise" in this, that the latter is the effect of a single shock, or of a series of shocks repeated without any regularity, while the sonorous sensation is that which we experience when the auditory nerve receives a certain number of vibrations which succeed one another after regular intervals of time. This is what takes place in the wheel of Savart, the siren of Cagnard-Latour, or by the vibrations of a stretched string, which occasion corresponding undulations in the air, which reach the ear, and strike the auditory nerve in the proportion of the number of shocks in a given time which belong to the movements of the sonorous body. The sharpness or graveness of a sound is owing to the greater or less degree of rapidity with which the vibrations succeed one another. 'The intensity depends upon the extent of the movements of the vibrating parts.

Wollaston and Savart tried to determine the limit at which sounds are perceptible to our ear or cease to be so, in consequence of becoming either too acute or too grave. Savart has shown that these limits are much more considerable than was supposed before his time, and that in order to perceive either very acute or very grave sounds, it is only necessary to aug ment their intensity. By passing to and fro with a certain rapidity a long bar of iron through a longitudinal cleft, which it almost entirely fills, seven or eight times in a second, a rather intense sound is obtained; and since at each passage of the bar there is a condensation of the air, succeeded by a rarefaction, the undulations constituting the sound are not more than fourteen or sixteen in a second. On the contrary, if we hold an elastic plate against a toothed wheel of large diameter, while in rotation, a very acute sound is perceived, even when there are 24,000 shocks in a second, in which case the sound is formed by 48,000 undulations. How complicated must be the structure of the organ of hearing, when we consider that its sensibility is preserved within such remote limits, and that its principal parts must vibrate in unison with sounds which vary from 14 to 48,000 undulations in a second!
According to the definition which has now been given of sound,we can easily explain how it happens that, by the coëxistence of two sounds, having the simple (numerical) relation of vibrations to each other,we perceive a deeper sound, which is a combination of the two. When this effect takes place, there are some instants in which the vibrations produced upon the auditory nerve by both these sounds coincide, and if these coincidences are sufficiently near, and regularly repeated, we have the sensation of a graver sound. When these coincidences are sufficiently seldom, or apart, which takes place when the sounds are not quite in unison with each other, we have only the sensation of the well-known phenomenon of beatings, first observed by Tartini.

Since it does not belong to my province to speak of that which relates to the act of consciousness produced by the excitation of the auditory nerve, I cannot enter upon the theories of music. If the sounds we hear simultaneously have a simple proportion to each other in the relative number of their vibrations, we experience the most agreeable sensations, or what are called harmonics, and the contrary errect takes place if these proportions do not exist. Experience teaches us that harmonious sounds are obtained simultaneously by twanging a large string, held in such a way as to make it yield the fundamental sound belonging to its whole length. We hence conclude, that the string divides itself into a certain number of parts, which vibrate separately and in the same time. We also know, that when we have sereral strings together, if their lengths bear a simple proportion to each other, we need only make one vilurate to obtain the sound belonging to their length from all the others. We may therefore conclude that the membrane of the tympanum, that of the fenestra ovalis, and perhaps also the extremities of the auditory nerve, may be the seat of harmonions sounds, and that the elasticity of these parts does not prevent these movenents. The contrary must take place with regard to the sounds we call discords.

\section{Qrígímal 暗ajers.}

AN ACCOUNT OF

TWO LABOURS OF A DWARF.

WITH SONE OBSERYATIONS ON THE OPERATION OF CRANIOTOMY, AND ON TIIE INDUCTION OF PREMATURE LABOUL.

By HENRY DAVIES, M.D.,

CONSCITING PHYSICIAN TO THE BRITISH LYING-IN HOSPITAL,

(Read before the Royal Medical and Chirurgical Society.)

THE subject of the following cases was the wife of a Spanish dwarf, (native of the Philippine Isles,) known and exhibited under the name of Don Santiago de los Santos. He was forty-nine years of age, and twenty-five inches high; his wife was twenty-nine years of age, and thirty-eight inches high, and of shorter stature than any other dwarf whose labours I have found recorded.* She was a native of Bimingham, where the partics were married, July $6 \mathrm{th}, 1834$, at both the Roman-catholic and Protestant churches. She appeared proportionably formed, was rather stout, and in excellent health. I was informed that in infancy she liad been sickly, and that the bones of her head were long closing; since then she had been perfectly well, and was active and animated. From the time of her marriage she had not menstruated. Ier mother, who was present, and residing with her at this time, was a healthy country woman, rather balow than above the middle size; her father mas said to be neariy six feet two inches ligh; and her brothers and sisters, of whom there were nine, tall and robust.

I visited her first in March, 1835 , at the request of $\mathrm{Mr}$. Bowden, then of Sloane-street, whom I agreed to assist when she was in labour. On the 14th of April, Mr. Bowden in. formed me, by letter, that labour came on at five o'clock in the morning. The membranes were ruptured at eight. I visited her at half-past three P.M. Her skin was cool; pulse tranquil; she passed urine freely; and her bowels had acted well. The os uteri was relaxed; the soft parts well imbued with moisture, and cool. The head was situated high up, above the brim of the pelvis, the conjugate diameter of which, measured by the hand, was more than two inches; the

* An account of these cases would have been presented to the Society at an earlier date, but I thought it probable that the dwarf, who remained and was exhibited in London for sereral years after her second labour, might have again become pregnant; she has not, however, been in that situation since. 
lateral spaces were larger; she had occasional, but not pressing pains.

April 15th.-Twelve A.n.: She had had active pains all night; the os uteri was fully dilated; the head moveable above the brim; the bowels had acted; and she had passed urine freely. The pulse was accelerated; she was tired and anxious, otherwise quite well. She had now been in labour thirty"-one hours, (but according to her own account, thirtyeight hour's, as she had bcen ill some time before Mr. Bowden mas sent for.) The head had not advanced in the slightest degree, and, from the comparative size of it and the pelvis, there appeared no probability of its passing in its entire state, it was therefore deemed advisable to perforate it, and break down the texture of the brain, which operation was done guardedly, with the perforator, and she was then left till four o'clock. Some of the contents of the head had by this time passed away, but the head had not at all advanced. A second perforation was now made, and all the oval portion of the cranimn brought away with craniotomy forceps; all the brain passed out; and the base of the skull was drawn down with the crotchet. She was left from seven till nine o'clock, during which interval, she had had some refreshing sleep, and had passed urive. Dr. $\boldsymbol{R}$. Lee now accompanied me, and kindly assisted in the operation. By persevering exertion with the crotchet principally, and craniotomy forceps, the base of tho skull was broken and torn away; subsequently, one superior extremity was bronght down, and then the other; afterwards, the thorax and abdomen were perforated, and their contents extracted. Considerable trouble was met with in delivering the foetal pelvis. The whole of the fœetus was at length, after much difficulty, brought away, great care being taken not to injure the uterus and vagina. The placenta was withdrawn in a quarter of an hour. The abdomen was bandaged, and in an hour, the patient was put to rights, and an anodyne was administered. The operation lasted upwards of three hours without intermission, and was most fatiguing. The foetus was a female, and of an arerage size.

The patient went on satisfactorily till the 18th of April, the third day, when, either from some error in her diet, (she had been eating four pudding,) or from the accession of milk, she had passed a restless night, and had headach, with confusion and hot skin. This was relieved by an aperient, (castor oil.)

On the 22 nd she had some pain and tension of the abdomen, particularly about the region of the caput coli, and over the uterus; pulse 100. Six leeches were applied, and on their removal a large bran poultice. A purgative was given, and some calomel, with opium, at bedtime, which was repeated the next night.

On the 25th, pulse 88; still some tenderness on pressure, and tumefaction of the abdomen. Six more leeches were applicd, followed by a bran poultice; some calomel and Dover's powder was given at bedtime.

From this period she progressed favourably, as if nothing musual had occurred in her labour, and was ont walking at the end of a month from her confinement, (May 12th.)

I did not see her again till August 25th, 1836, when she called at my house. She had the usual symptoms of pregnancy - amenorrhoa, nausea, enlargement of the mamma, and prominent abdomen. She thought she felt a feeble movement in the right ilio-pubic region; her general health and appearance was good, and she had menstruated regularly from the time of her recovery (when she went into the country) till that of her return to her husband, about eighteen weeks since. On examination, the os uteri was high up, (an apparent fissure in its right side;) on the right, above the cervix, a small, firm body, was felt, and presumed to be the foetal head. The measurement of the antero-posterior diameter of the pelvis, both by the hand and callipers, was rather more than two inches-somewhat larger on the sides from each sacro-iliac junction to the pubes. I agreed to induce premature labour, provided she could engage the attendance of MIr. Bowden, (whose patient she had formerly been,) as she was then residing in Holborn.

These circumstances being arranged, I saw her from time to time; and on the 20th of October-twenty-seventh week of her presnmed pregnancy-she took an active aperient, (compound senna mixture, with decoction of aloes.) On the day following, at three o'clock P.M., I dilated the os uteri with the finger, and passed up the perforator two inches above it posteriorly; then directing the point of the instrument forwards till I felt a degree of resiliency, (indicating the presence of the membrane distended with fluid,) I punctured the membranes, and let off a small portion of liquor amnii,--say, half an ounce,- -and withdrew the instrument desiring the patient to move about as usual. Symptoms of labour came on twenty-four hours after; and on Sunday morning, Oct. 23rd, Mr. Bowden writes to me,- "I delivered our little patient of a dead child, right foot inverted, at halfpast six this morning, and removed the placenta a quarter of an hour afterwards. She had been in strong labour all night, and her pains first became urgent about three o'clock yesterday afternoon." Her recovery was satisfactory in every respect.*

In her first labour, as there was some probability that the fotus might be of a proportionate size to that of the parents, and from the general good state of health of the mother, it was not deemed advisable to interfere with the progress of gestation; yet so painful a labour was not anticipated.

It is an admitted fact, I believe, that however Nature may be now and then fantastic in her productions, she rarely or never perpetuates the same to a second generation; and this law was borne out here.t

It is stated that the protestant clergyman hesitated to marry them, on the presumption that it was contrary to the canon law, as being the means of propagating a race of dwarfs; but in this he was overruled by the high bailiff of Birmingham, and some legal opinions.

It may be observed here, that although this patient was in excellent healih, and of active habits, she had been sickly during her infancy, at which time her pelvis most likely became deformed, although this was not observable in her general appearance. At the utmost, however, the conjugate diameter was barely two inches and a half. It is remarked, that deformity of the pelvis from rickets, during infancy, always remains stationary; but in those who suffer from spinal distortion in after-life, the pelvis is not necessarily affected. Hence, in many cases where, from the distorted appearance of an individual, a difficult labour might be expected, the infant passes with facility. I do not adduce cases to prove this, as such, on reflection, will occur to every practitioner.

After the labour had lasted a definite time, when $\mathbf{M r}$. Bowden and myself felt assured that the infant was not likely to be born by the unassisted efforts of Nature, and as the head was not so far advanced as to be within reach of the forceps, it was deemed advisable, betore her situation became jeopardized by the supervening of dangerous symp toms, to perforate the head, and then to leave it for a time, in the hope that, the more bulky part being removed, the remainder would be pressed down by the labour-pains; and this practice, where such delay is from all other circumstances admissible, has its advantages: the risk of morbid jamming the cranial bones being removed, the soft parts are not injuriously pressed upon, and the trunk \&c. moulds itself to the passage.

This practice was followed by Dr. Clarke, in the labour of Elizabeth Sherwood, $\neq$ in November, 17\%6. The head was perforated on Tuesday, she was delivered on Wednesday morning, at ten o'clock: also in that of Ann Cooper, in July, 1785. The head was perforated at three o'clock on the 20th, and the delivery terminated on Thursday morning at ten o'clock, on the 21st. Also in that of West, in Nov. 1785: the head was perforated on Saturday, the 5th, at four o'clock P.Mr., and the delivery terminated on the day following. $\$$

The following case is also in point:- Mrr. B_- was taken in labour at half-past one o'clock, 16th of May last, (1846, when the membranes broke spontaneously; the presentation was situated so high as not to be satisfactorily made out: it was subsequently ascertained to be the face. Labour went on, the liquor amni dribbling away. At four P.M. on the $17 \mathrm{th}$, I was requested by Mir. Woolly to see her. The head was firmly jammed at the brim of the pelvis, the long axes of the two corresponding, the chin on one side, and the occiput on the other, from which situntion it never moved till after it was perforated; the bowels had been acted upon by a purgative, and the urine drawn off by the catheter several times. Under these cir-

* See a case in the British and Foreign Medical Review, vol. x. p. 272. The dwarf was thirty-nine inches high; her husband of ordinary stature. The dwarf was thirty-nine inches high; her husband of ordinary stature.
In her first labour she had convulsions. Delivery was first attempted by means of the forceps, and was subsequently effected by the operation of means of the forceps, and was subsequently effected by the operation of
craniotomy; there was some laceration of the soft parts, and afterwards craniotomy; there was some laceration of the soft parts, and afterwards
inflammatory symptoms. Her second labour was induced prematurelythe pelvis being nearly three inches in its antero-posterior dameter. The the pelvis being nearly three inches in its antero-posterior d.an
infant, though feebly born, was quickly recovered, and lived.

+ For the following I am obliged to Dr. Pidduck :- " The children of dwarfs do not necessarily partake of the diminutive size of their parents. There was a well-known instance of a glover and his wife, who lived opposite the infirmary in Edinburgh : their height did not exceed forty inches ; their only daughter was at least five feet high, and so robust as to be able to carry both her parents, one on each arm, at the same time." 
cumstances, it was determined to perforate the head, which Mr. Woolly did through the forehead, near the anterior fontanelle, at five o'clock, and got out as much of the brain as was possible. All her unfavourable symptoms disappeared. Some secale cornutum was given, but no efficient pains were produced. At half-past ten o'clock some degree of collapse had taken place, and the chin had descended a little; she seemed disposed to sleep, and was left till the following morning. At six o'clock some pains came on; the face had descended lower in the pelvis, and the head was then delivered by the crotchet. Mr. Woolly says, in two minutes the remainder of the fotus followed, but from want of uterine action the placenta was delivered artificially; the whole labour was terminated at half-past seven o'clock. The patient recovered satisfactorily, and shortly after went into the country for some time, and is now again (November) pregnant.

It is a very material consideration, in all cases requiring the operation of craniotomy, that the commencement of the operation should not be delayed, after we have carefully considered all the circumstances of the case, and are convinced of its necessity. No patient ever did, or, in general, ought to, suffer from the operation, when performed in due time, and with moderate care; and indeed, for the most part, women after such operations recover particularly well; but most deplorable are the consequences when the operation is delayed too long, or performed with violence : within the last two months I have been witness to two deplorable cases, rendered fatal, I believe, from delay only. In the performance of the operation, besides the perforator and crotchet, the craniotomy forceps, with teeth or points on the inner surface of the blades, will be found a most useful and powerful instrument; the blades should be separate, and lock, as the common midwifery forceps do, by which their application is much facilitated. I first met with them at a sale of the late Dr. Clough's obstetrical instruments, twenty-five years ago, but these were inapplicable from the joint being fixed; the better-formed are those which $I$ believe Dr. Ramsbotham mentions as improved by the late Mr. Holmes. I also, at the same time, got an instrument, which is, I believe, a guarded crotchet; the guard is moveable, and a very well-cut piece of hard wood is adapted to the space left, that the instrument may be used without the guard. I have in vain sought to discover auything like it in the book of plates of instruments, at the College of Surgeons, or elsewhere.

It is now generally admitted, that in the majority of cases of moderately diminished or distorted pelvis, or in those where the cavity is encroached upon by adventitious structures, (thus preventing the head of a full-grown fotus being born,) it is advisable to induce labour artificially, at a premature period, on the presumption of its utility and general safety. To render the operation successful, it should be performed earlier or later, as the conjugate diameter of the pelvis may vary from two inches and a quarter to three inches. The operation already detailed is an instance of the first. The following, in consequence of the presence of fibrous tumour, will illustrate the second:-

This patient's first child was still-born, after a difficult and protracted labour, from the presence of a firm (I presume) fibrous tumour, situated at the posterior part of the uterus, above the cervix. When I first saw her (May, 1833) she was in the sixth month of her second pregnancy. On examination, I found the os uteri high up anteriorly, a firm tumour above the os resting on the brim of the pelvis posteriorlyperhaps a little more on one side than the other-and which diminished the superior aperture to apparently less than two inches. At the seventh and a half mont the membranes were punctured, as before described, and an active purgative given. The liquor amnii dribbled away at intervals. At the end of forty-eight hours (the termination of the second day after puncturing the membranes) labour-pains commenced, which eventually became most severe and forcing. At first it appeared physically impossible that the head could pass, and craniotomy was thought of. At length the head, being compressed, gradually came down, the tumour receded somewhat, and the flattened head slowly advanced. In about fourteen hours from the commencement of labour, the infant was born. By a little attention it was enabled to respire, the head gradually recovered its proper shape, and both patient and child did well.

There may be other states, not affecting the pelvis in particular, in which it may be justifiable to induce premature labour; but these do not necessarily come within the scope of this paper.

Admitting the propriety of inducing premature labour, there are certain considerations that must be kept in view, before determining on the operation:-
First. That the operation should not be had recourse to until experience has proved the impossibility of the patient's bearing a full-grown fotus alive.

Secondly. The operation should not be had recourse to unless the patient be in a state of average health, for her constitution and generative system not being at this premature period prepared for the process of labour, she is exposed to a greater degree of hazard than would exist at the full period of utero-gestation.

Thirdly. If, upon examination, before the operation is performed, it should be discovered that the presentation is preternatural, it is advisable to defer it for a few days, as it is possible that a spontaneous alteration in the foetal position may take place, particularly if the position be that of the superior extremities.

Fourthly. That a wet-nurse be in readiness, in order that the infant may have the most appropriate nourishment from the first, so as to give it the most favourable chance of surviving: *

Of the Operation.-The object is to assimilate the process as much as possible to that of natural labour; with this view, it is desirable to keep the membranes as nearly as possible entire, by which means you save the infant from injurious pressure, and have the soft bag of membranes to assist in dilating the os uteri, \&c. Various modes have been proposed.

First. By dilating the os uteri with the finger, and detach. ing the membranes contiguous to it by means of an elastic gum catheter, and immediately afterwards giving an active aperient in combination with tartrate of antimony. I recorded a successful case of this method in the Medical Repository for 1825, not being aware at the time that a sinilar operation had been performed by Dr. Hamilton, and some other practitioner.

Secondly. By puncturing the membranes high up, in the mode described in the two cases detailed above.

Thirdly. By the administration of the secale cornutum, of which there are several successful cases recorded in the medical journals.t In general I have been disappointed in it, but $I$ was induced to try it again on a most farourable subject, in the British Lying-In Hospital, whose previous labours had been several times prematurely brought on; she was not delivered till the fifth day after its exhibition; that is, from the 2 nd to the 7 th of February. It is but just that I should recount the last and only case in which it succeeded well.

A. D—, aged twenty years, a remarkably stout, hale woman, had been previously delivered of two children by the operation of craniotomy, of the last of which I delivered her, after a very protracted labour, although I conld not detect any deformity of the pelvis. I was supported in my opinion in the propriety of the operation by that of Dr. R. Lee.

In her subsequent pregnancy, March, 1845, she applied to me at the middle of the eighth month, to induce premature labour. I gave her two active purgatives, but I could not discover the os uteri, neither conld Dr. $\boldsymbol{R}$. Lee or Dr. Dyer. In the hope of bringing it within reach of the finger, $I$ ordered her one scruple of secale cornutum in powder every six hours; she took five doses without any apparent effect whatever. Shortly after taking the sixth dose, active labour-pains supervened, and she was delivered in two hours of a healthy male infant.

Fourthly. By plugging the os uteri with sponge tent, to canse its dilatation, as recommended by Professor Kluge.+

Fiftlly. By plugging the upper part of the ragina. Dr. Schoeller was led to do this from having observed, that when used to suppress hæemorrhage, in cases of placental presentation, or of threatening abortion, it had a considerable infuence in exciting uterine action. In one case where he employed it to suppress homorrhage, it was followed by premature labour. Dr. Schoeller recommends filling up the vagina with balls of charpie, which, for the sake of cleanliness, should be removed every twenty-four hours; the action of the uterus is usually speedily excited, and when fully established, the plug may be withdrawn, and secale cornutum administered, to prevent the diminution of labour-pains. The finger may likewise be used to assist the dilatation of the os uteri; but great care must be taken to leave the membranes uninjured. Five cases are related: in four, the children were born alive; the fifth was still-born, from the breech presenting. The

* See vol. iii. Transactions, p. 143. Dr. Merriman's cases of labour ar tificially induced.

+ Dr. Ramsbotham, Med. Gazette, June 28, 1834 ; Dr. James Paterson, of Glasgow, Med. Gazette, June 1, 1839, p. 332; H. Hume, of Gloucester, Med. Gazette, Jan. 7, 1839, p. 639; Ingleby's Obstetrical Medicine, p. 232. $\ddagger$ British and Foreign Medical Review, July, 18 40 , p. 272 . 
average length of time which elapsed between the application of the plug and the birth of the infant was five days fourteen hours.**

On reviewing the different modes of effecting this operation, I am induced to give the preference to the second, or that detailed in the labour of the dwarf, and in the one with the fibrous tumour, as being the most simple, most effectual, and least tedious. The perforator I have used (which is on the table) was invented by the late Mr. Holmes; and in the majority of the following number of cases the above instrument was employed:-

Fifty cases: twenty-two boys and twenty-eight girls; of whom twenty-six were born alive, and lived-eleven boys and fifteen girls; nineteen were still-born-ten boys and nine girls; five died a few hours after birth-one boy and four girls. Thirty-six presented the head; five, the breech; one, breech and feet; two, the feet; three, the arm; three, the funis. Two were delivered by the operation of craniotomy.

In one of the cases delivered by the operation of craniotomy, the patient had been allowed to complete the eighth month of her preguancy. The child presented the breech. After the delivery of the body, the head was so completely jammed in the pelvis as to render the risk of wounding the soft parts, by perforating the back of the head, very great; the perforator was passed up through the roof of the mouth, and the contents of the head extracted; the head was shortly after delivered, without any apparent mutilation when the mouth was closed.

This woman has siruce borne ten children in the middle of the seventh month of pregnancy: five were born living, of whom three died during childhood; and two are young women, about whom I have been consulted since the preceding part of the paper was written. The latter ten labours of this woman are not included in the fifty cases above mentioned, as she was residing in a different part of the town, and not under my care.

A great portion of these children were nursed by their parents; but for the most part the mothers in these cases are not efficient nurses.

The majority of the above children, of whom $I$ have been enabled to make inquiries, are still living, between sixteen and three years of age, and have all average health.

REMARKS ON DR. TODD'S PAPER ON THE

\section{"IRRTTABILITY OF PARALIZED MUSCLES."}

(PUBLISHED IN VOLUME XII. OF THE MEDICO-CHIRURGICAL TRANSACTIONS.)

BY W. TYLER SMITH, M.B.

Is this paper, Dr. Todd has devoted himself to prove Dr. Marshall Hall wrong in believing that the state of irritability of paralyzed muscles, as tested by galvanism, is of use in the diagnosis of cerebral and spinal paralysis. Dr. Marshall Hall, as is pretty well known, believes, that in cerebral paralysis the muscular irritability, as tested in this way, is augmented, while in spinal paralysis it is diminished. Dr. Todd has arrived at a different conclusion. Experiment is the basis of both opinions; but I wish to point out, that the experiments of Dr. M. Hall and Dr. Todd are not the same, and that this difference of opinion may be attributable to the difference in the nature of their experiments; or that, at all events, before any positive conclusions can be arrived at, the experimental differences must be taken into account. Dr. Marshall Hall experimented with a simple galvanic trough, carefully insisting on the necessity of using a few plates only. In Dr. Todd's experiments the "electro-dynamic machine was used, which was supplied with a single cell of Baniell's constant battery," and latterly he has employed "the magneto-electric rotation machine." In an experiment which Dr. Todd details from Dr. Novelli, Dr. Todd says this gentleman " used a trough of fifty plates." Thus the experiments narrated by Dr. Todd and Dr. Marshall Hall are essentially different, and for anything which yet appears, both series of experiments and facts may be perfectly correct. Dr. Marshall Hall has been careful to use a weak and continued current; Dr. Todd has relied on a strong and intermittent one. Having witnessed and assisted at a considerable number of Dr. M. Hall's experiments, I could, if that were necessary, bear testimony to their perfect truth. I took notes of certaimly as many cases as those detailed by $\mathrm{Dr}$. Todd, all of which it is not necessary to relate at length, but the following is one of them:-

* British and Foreign Medical Review, No. xxv. Jan. 1843.
On Feb. 15th, 1846, Mr. B-, a surgeon in practice in the country, was examined. He has at this time hemiplegia of the right side, of gradual origin. Two years ago, slight weakness would occasionally be felt in the right leg after a long walk. From this, partial paralysis, extending to the right upper extremity, developed itself, and had, up to the present date, been increasing. The nutrition of the side affected had suffered considerably, owing to the gradual accession and chronic form of the paralysis. The wasted and lax state of the muscles in this case, would, $\grave{a}$ priori, have been considered unfavourable to the preservation of the muscular irritability in the limbs affected.

The relative amount of the muscular irritability in the two upper extremities were first tested, a common galvanic trough being the instrument employed in the experiment. The hands were suspended equally in a basin of plain water, and a clean copper penny-piece placed on the upper part of the sternum. One pole was then introduced in the water of the basin, and the circle was completed by touching the copper piece with the other. The battery used was a small one, consisting of fifty plates.

At the closing of the circle, when a few plates only were used, the paralyzed limb was moved very distinctly, while the healthy limb was not at all moved. This was distinct and unmistakable. When a large number of plates were used, the completion of the circle affected both limbs, but the paralyzed limb was more powerfully contracted than the other. These experiments were repeated several times. on this occasion, and with the same results.

The inferior extremities were now galvanized. Plain water was at first put in the basin which held the feet, but no movements in either limb were excited. The patient had been walking, and this may have been one reason why the muscular irritability in the lower extremities should have been so much less than in the upper, though the lower limbs are always less affected by galvanism. A solution of salt and water was now substituted for plain water, salt and water having the power of increasing the contact. The two feet were placed in one basin, and the two hands in another. One wire being placed in the foot-basin, the circle was closed at short intervals by dipping the other pole into the basin in which the hands were placed. When the toes were in the hollow of the basin, the paralyzed foot was first and most affected; when the toes were made to rest on the edge of the basin, the effects were doubtful, probably from the mechanical support afforded by the basin. In these, as in the experiments of the upper extremities, a small number of plates were first used, and then the galvanic power was increased gradually.

February 17th.-The same battery, and a solution of salt and water, were used on these occasions, in the experiments on the upper as well as the lower extremities. The limbs being arranged, a small number of plates again moved the hemiplegic arm distinctly, before any contractions could be observed in the sound limb. As before, when the number of plates were increased, the paralyzed arm was moved more energetically by the shock than was the healthy arm.

The feet were now placed in a wide, shallow dish, containing salt and water. A much larger number of plates were required to move the legs in the first instance. When the effect of the galvanism became perceptible in the legs, the gastrocnemins of the paralyzed limb contracted distinctly, when no motion could be observed in the same muscle on the sound leg: The tibialis anticus conducted itself in exactly the same manner. These experiments were repeated again and again at this visit, with uniformly the same result.

Mr. B- mentioned a fact for which he was puzzled to account-namely, that on cold, frosty days, the voluntary power over the paralyzed side, and the muscles themselves, were apparently stronger than at other times. He had been struck the more by this, as it seemed inconsistent with the cause assigned to his malady by himself and other professional friends whom he had consulted-i. e., congestion of the brain. He had supposed that, this being true, cold ought to have increased the congestion, and, consequently, the paralysis.

Spinal physiology affords an easy solution of this difficulty. In ordinary locomotion, every voluntary muscular action induces, in addition to the cerebral voluntary action, a refiex spinal action of the muscles employed. When cold is applied to the surface, the muscular contractions in voluntary motion are more powerful than at other times, because, for one reason at least, the voluntary motion is aided by an increase of the reflex motion. Thus, we can walk better against a moderate wind than when there is a perfect calm; or, to take a more forcible illustration, the muscles of a clipped horse are seen, 